\title{
AMPICILLIN TREATMENT OF TYPHOID CARRIERS
}

\author{
A. B. Christie \\ Fazakerley Hospital, Liverpool, 9.
}

THE change in the clinical course of typhoid fever due to treatment with chloramphenicol has been one of the more dramatic triumphs of the antibiotic age. A prolonged fever has been converted into a short sharp febrile illness, so that the patient suffering from the disease, instead of being dangerously ill for several weeks, may well be sitting up in bed after three or four days on chloramphenicol therapy. The organism causing his disease has been shown in vitro to be sensitive to chloramphenicol, and the clinical response to its administration seems to correspond well with the in vitro sensitivity. However, the patient, who has responded well to chloramphenicol, may continue to excrete the Salm. typhi even though repeated courses of the drug are given and the organism remains sensitive on in vitro testing. Unfortunately the problem of the typhoid carrier has not been solved by chloramphenicol. Have we, in ampicillin, a more satisfactory answer?

\section{Eight Carriers}

Early in 1962, a patient died in a mental hospital, her illness being diagnosed at postmortem as due to typhoid fever. Shortly afterwards a nurse from the same ward was operated on for appendicitis: she had a stormy convalescence, punctuated by a bout of cholecystitis, and her illness was eventually diagnosed as typhoid fever. As a result of enquiries in the mental hospitals in the area, eighteen patients were transferred to Fazakerley (Infectious Diseases) Hospital, Liverpool, as suspected typhoid carriers, and seven of these were eventually proved to be carriers. An eighth carrier, completely unrelated to the mental hospital episode, came under my care about the same time. This patient who gave no history of typhoid worked in a school canteen where she had infected a schoolboy. In addition she had also recently infected her husband and son-in-law. The present report deals with the investigation and treatment of these eight carriers.

\section{History of the carrier state}

Six of the seven mental hospital patients had been in hospital continuously for periods of $7,17,20,31,36$ and 47 years: they had been known carriers for 7, 12, 12, 13, 26 and 27 years. They had all had previous treatment for their carrier state, most of them severa亲 times - with penicillin and sulphonamideses? streptomycin, furoxone and chloramphenicos with and without corticosteroids. Without giving details, I can state that the dosage and duration of the treatments had been thorough? though without results. The seventh mentat hospital patient had been in hospital 36 years but she has been a known typhoid carrier on since 1962; there is a vague history of he having been a carrier for 11 years previously요 but this cannot be confirmed from her notes and there are no records of previous treatmen The eighth carrier, the school canteen worker? was discovered only after she had infecteo three contacts; she gives no history at all of any relevant history so that the duration of her carrier state is unknown.

Preliminary Surveillance

It seems desirable to survey the patients bacteriologically for a fairly long period in ordeep to establish the excretion pattern of eash carrier before starting treatment. In the casses of the mental hospital patients this was exfy? for they had all been in hospital for many years, and a few months made no difference to them. During five months observation the seven carriers excreted Salm. typhi in 11 ouf of 43 to 43 out of 44 fæcal specimens: details of each patient are shown in Table II. With the eighth carrier, it was not possible to carry out such long observation, but for two monthe during part of which she was on treatmen? with chloramphenicol, she excreted Salmo typhi in 31 out of 31 specimens.

Treatment with Ampicillin

It was decided to treat the patients wit ampicillin by mouth for three months supplemented throughout by probenecid ${ }_{\odot}$ During the first week oral therapy was sup plemented by intramuscular injections:

TABLE I

Typhoid Carriers.

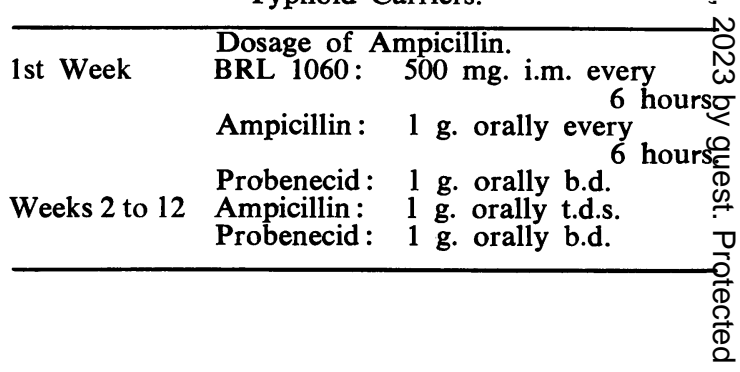


ampicillin was not then available in injectable form, and BRL 1060 (a mixture of the $\mathrm{D}$ and $\mathrm{L}$ isomers of $\alpha$-amino-benzyl penicillin) was used instead which is only slightly less active than ampicillin - the D isomer. (Ampicillin is now available in injectable form). The scheme of treatment is shown in Table I.

\section{Toxic Effects}

Within the first fortnight, two patients developed erythematous rashes, with scattered petechial elements. They were not otherwise upset and their blood counts were normal. Treatment was not altered and the rashes disappeared. One of the two has subsequently had two further courses of treatment with ampicillin with no evidence of sensitivity. No other toxic reactions in any of the patients to the treatment were observed.

\section{Results and Follow-up}

All eight carriers became abruptly negative within three days of starting treatment, and seven of the eight have remained negative for a year. Six of these seven are still in hospital, and from each, 100 fæcal specimens have been examined and all are negative. The seventh patient, the canteen worker had to be allowed home, and surveillance with her could not be so thorough: nevertheless we kept her under observation for nine months, and 34 out of 34 specimens of fæces were negative.
With the eighth carrier, the story is different. Before treatment, 43 out of 44 specimens had been positive over a period of five months. Specimens became negative immediately treatment commenced, they remained negative throughout the three months course and for three months thereafter, a total of 44 out of 44 specimens being negative. She then began to re-excrete Salm. typhi, and during a month's observation, four out of eight specimens were positive. She was then put on treatment again with oral ampicillin $1.5 \mathrm{~g}$. every six hours and probenecid $1 \mathrm{~g}$. twice daily for one month. Specimens immediately became negative and remained negative for three months after treatment, 36 out of 36 specimens being negative. She then began again to excrete Salm. typhi and in a period of three weeks, six out of six specimens were positive. Straight $\mathrm{X}$-ray of the abdomen showed no gall-stones, but Salm. typhi was isolated from bile obtained by a duodenal tube. She has again been put on treatment, and specimens have again become negative. Further X-ray investigation of her gall-bladder, the sensitivity of the organism to ampicillin, and the concentration of the drug in her serum and bile are being investigated.

\section{Details of the Patients}

The data regarding the eight patients, with details of their past histories and their response to treatment are summarized in Table II.

TABLE II

Typhoid Carriers.

Effect of Treatment with Ampicillin.

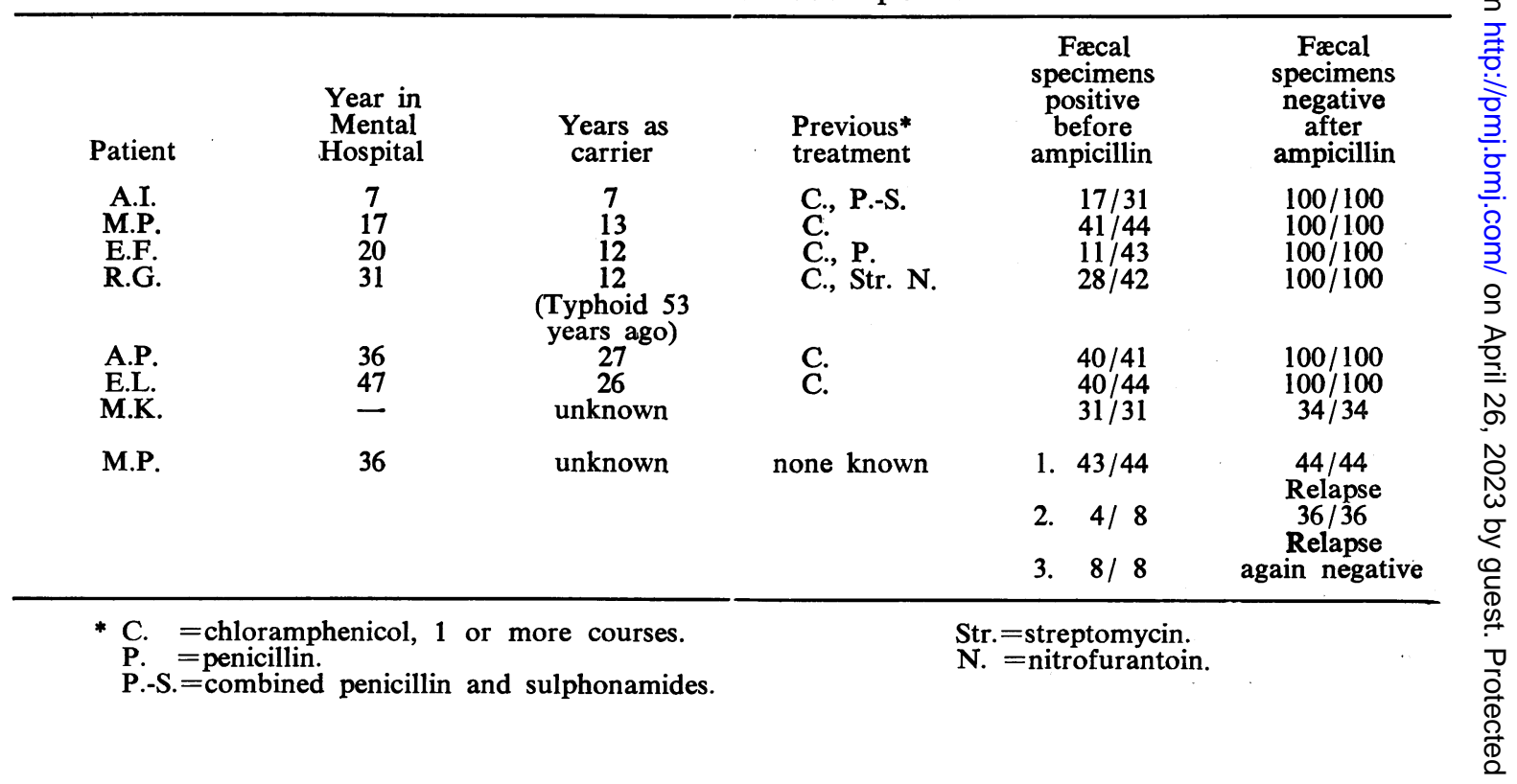


Vi Agglutination Titres

Specimens of blood were taken from six of the patients one year after the commencement of ampicillin treatment. The Vi agglutination titres, correlated with the length of the carrier state and the response to treatment are shown on Table III.

\section{Comment}

I do not know how one decides that the typhoid carrier state in a patient has ended. The number of negative specimens must always be an arbitrary criterion. In the past, when bacteriological technique was less perfect than it is now, three negative specimens were often accepted as evidence of cure, and the records of these patients in their long years in mental hospitals are scored at intervals with three red lines, indicating that three negative specimens had been obtained; although the fact that these tests were repeated again and again show that the medical administrators of the hospitals knew too much about the typhoid carrier state to accept three negatives as proof of cure. Those of us who have spent many years in infectious diseases hospitals share their scepticism. Yet faced with a patient whose specimens, before treatment, were positive 43 times out of 44 , but negative, after treatment, 44 times out of 44 , most doctors experienced in epidemiology would have begun to hope that the carrier state had come to an end. Yet my patient relapsed after 44 specimens, six months after the commencement of treatment, and again after another 36 negative specimens, almost exactly a year later.

The significance of the $\mathrm{Vi}$ antibody test has never been fully established, and its value has recently been questioned (Bokkenhauser, 1964; P.H.L.S. Working Party, 1961). If one accepts the conventional interpretation, that a titre over one in five indicates the presence of Salm. typhi in the body, then five out of six patients I have tested must still be regarded as carriers, although four of the five have had 100 consecutive negative fæcal specimens over the past year. But it may well be that where Vi antibodies have been established as a result of antigenic stimulation spread over periods of seven to 26 years, they may be more difficult to dislodge from the serum than Salm. typhi, their antigen, from the fæces.

Seven out of eight typhoid carriers have been persistently negative since they were treated with ampicillin. The eighth carrier has
TABLE III

Vi Agglutination Tests. One Year After Ampicillin Therapy.

\begin{tabular}{|c|c|c|c|}
\hline Patient & $\begin{array}{l}\text { Years as } \\
\text { Carrier }\end{array}$ & $\begin{array}{l}\text { Number of Negative } \\
\text { Fæcal Specimens }\end{array}$ & 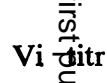 \\
\hline $\begin{array}{l}\text { A.I. } \\
\text { M.P. } \\
\text { E.F. } \\
\text { R.G. } \\
\text { E.L. } \\
\text { M.P. }\end{array}$ & $\begin{array}{r}7 \\
13 \\
12 \\
12(? 53) \\
26 \\
?\end{array}$ & $\begin{array}{c}100 / 100 \\
100 / 100 \\
100 / 100 \\
100 / 100 \\
100 / 100 \\
44 / 44 \\
\text { Relapse } \\
36 / 36 \\
\text { Relapse }\end{array}$ & 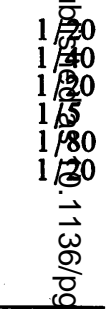 \\
\hline
\end{tabular}

not been cured, but there has been a verys marked change in her excretion pattern Further surveillance is obviously required No claim is made that any carrier has beerp cured; but I think one is amply justified ing claiming that ampicillin has had a most profound effect on the carrier status of my eight patients.

\section{Addendum}

In six of the seven mental hospital patiens radiological examination of the gall-bladdee has now been carried out. In five of the six $\overrightarrow{0}$ gall-bladder function appears to be normal though in one of the five there is at least ope small non-opaque stone. In the sixth patiento A.I., the gall-bladder appears not to be functioning, though further X-ray examination is required: her Vi was positive at one in $20 \%$ and she has had 100 negative fæcal specimens in the past year.

In the case of the relapsing patient, the gall-bladder appears to be functioning normally though Salm. typhi has been cultured in bile. obtained by duodenal intubation. We had great difficulty in intubating this patient second time for assay of ampicillin in the bile and it was 15 hours after her last dose before a sample was obtained: ampicillin was then present in a concentration of $1.3 \mu \mathrm{g} . / \mathrm{mL}$ In her serum, ampicillin was present at $1 \mathcal{F}^{2}$ $\mu \mathrm{g} . / \mathrm{ml}$. 45 minutes after an oral dose of $1.5 \mathrm{~g}$ ampicillin, and $23 \mu \mathrm{g}$. two hours after the dose There is no obvious reason at the moment fob her relapses.

\section{REFERENCES}

BoKkenhauser, V. (1964): Amer. J. publ. Hlth., 54요 477.

Public Health Laboratory Service Working Partî (1961): J. Hyg. (Lond.), 59, 231.

This paper is based on a previous publication in the British Medical Journal (CHRISTIE, A. B. (1964), B.M.J., 1609), and is published by kind permission of the Editor of the British Medical Journal. 